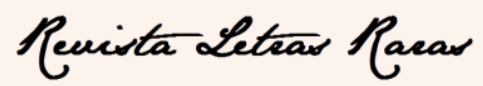

ISSN: 2317-2347 - v. 8, n. 3 (2019)

\title{
REICHMANN, C. L.; GUEDES-PINTO, A. L. (org.) Horizontes (im)possíveis no estágio: práticas de letramento e formação de professores de língua. Campinas, SP: Pontes, 2018. 278p.
}

Bruno Alves Pereira*

Recebido em 20 jun. 2019. Aprovado em 25 ago. 2019.

Se, há poucos anos, observávamos o lançamento de livros cujos capítulos falavam sobre o estágio supervisionado em diferentes licenciaturas (português, matemática, química, etc.), atualmente, temos presenciado a publicação de coletâneas cujos capítulos focalizam, especificamente, o estágio na formação de professores de línguas, como Estágio, escrita e formação, organizada por Valdir Heitor Barzotto e Émerson de Pietri, e Horizontes (im)possíveis no estágio: práticas de letramento e formação de professores de línguas, organizada por Carla Lynn Reichmann e Ana Lúcia Guedes-Pinto.

Publicado no final de 2018 pela editora Pontes, o livro Horizontes (im)possíveis no estágio possui uma apresentação feita pela Angela Kleiman, professora titular aposentada do Departamento de Linguística Aplicada da Universidade Estadual de Campinas (Unicamp), e dez capítulos de autoria de pesquisadores, cujas trajetórias profissionais estão profundamente relacionadas ao estágio supervisionado em cursos de formação de professores de línguas em diversas partes do Brasil (São Paulo, Minas Gerais, Paraíba e Rio Grande do Sul) e do mundo (África do Sul e Emirados Árabes Unidos).

As organizadoras do livro também possuem seus caminhos acadêmicos marcados pelo estágio supervisionado: são professoras desse componente curricular em universidades brasileiras públicas e, nos últimos anos, têm realizado e orientado investigações importantes sobre esse espaço da formação docente. Carla Reichmann,

\footnotetext{
*Universidade Estadual da Paraíba, Monteiro, Paraíba, brunoapcg@bol.com.br
} 


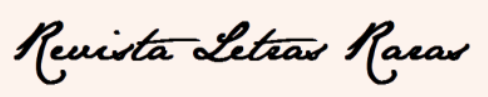

ISSN: 2317-2347 - v. 8, n. 3 (2019)

professora associada da Universidade Federal da Paraíba (UFPB) onde atua no Departamento de Línguas Estrangeiras Modernas e no Programa de Pós-Graduação em Linguística (Proling), investigou, por exemplo, o estágio supervisionado do curso de Letras-Inglês da UFPB no pós-doutorado realizado na Unicamp sob supervisão da professora Angela Kleiman entre 2011 e 2013. Entre as publicações de Reichmann resultantes desse período, está o livro Letras e letramentos: escrita situada, identidade e trabalho docente no estágio supervisionado, publicado em 2015 pela editora Mercado de Letras. Já Ana Lúcia Guedes-Pinto, professora titular da Unicamp onde atua na graduação em Pedagogia e no Programa de Pós-Graduação em Educação, defendeu, em 2011, tese de livre-docência sobre a escrita de pedagogos no contexto do estágio supervisionado. Em 2015, uma versão dessa tese foi publicada sob o título de Práticas de escrita na formação de professores: indícios de apropriação da profissão docente pela editora Mercado de Letras.

A seguir, passamos a abordar brevemente cada um dos capítulos do livro. No primeiro, Luzia Bueno, professora da Universidade São Francisco e autora de uma das primeiras teses brasileiras sobre estágio supervisionado na perspectiva da Linguística Aplicada, Kátia Diolina e Rogério Tomaz, pesquisadores ligados ao Programa de PósGraduação em Educação da Universidade São Francisco, a partir dos fundamentos do Interacionismo Sociodiscursivo, da Ergonomia Francesa e da Clínica da Atividade, investigam o papel do professor supervisor no contexto de estágio supervisionado estabelecido pela Resolução 02/2015 que define as Diretrizes Curriculares Nacionais para a Formação Inicial e Continuada em Nível Superior de Profissionais do Magistério para a Educação Básica.

No segundo capítulo, “A professora no dizer da estagiária: algumas potências no/do estágio na formação inicial de professores”, Ana Lúcia Guedes-Pinto e Gilka Fornazari Batista, ancoradas na perspectiva da História Cultural e nos estudos bakhtinianos, observam relatórios produzidos na disciplina "Prática de ensino e estágio supervisionado nos anos iniciais do ensino fundamental" do curso de Pedagogia da Unicamp ministrada conjuntamente pelas autoras. A partir da análise de aspectos linguísticos desses textos, Guedes-Pinto e Batista identificam tanto conflitos e tensões que ajudam a forjar a identidade docente das autoras dos relatórios quanto a apropriação de um dizer próprio do ambiente acadêmico. No terceiro capítulo, Juliana Alves Assis, 


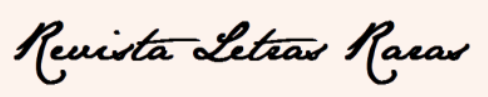

ISSN: 2317-2347 - v. 8, n. 3 (2019)

professora da graduação e da pós-graduação em Letras da Pontíficia Universidade Católica de Minas Gerais (PUC-Minas), apresenta uma investigação sobre um tema recorrente em suas pesquisas nos últimos anos: a representação social. Partindo de uma fundamentação teórica que engloba estudos da Psicologia Social e de uma perspectiva discursiva da linguagem, Assis analisa respostas dadas por alunos de Letras-Português, no início e no fim de um componente de estágio supervisionado em uma universidade mineira, à seguinte pergunta: o que é um bom professor?

Em “"Entrei com a ideia desastrosa de que tudo daria errado, e...': relato de experiência sobre o estágio supervisionado de um curso de Letras", Marília Curado Valsechi, também autora de uma tese de doutorado sobre o estágio supervisionado no curso de Letras, verifica, a partir da perspectiva teórica dos Estudos do Letramento, marcas linguístico-discursivas que indicam a transformação de "aluno de graduação" em "professor" vivenciada durante o estágio. O corpus em análise é composto por relatórios produzidos por alunos do período noturno de uma disciplina de estágio de Língua Portuguesa de uma universidade pública paulista. Seguindo os pressupostos da Análise Crítica do Discurso e da educação reflexiva de professores de línguas recorrentes em sua produção acadêmica, no quinto capítulo, Luciani Salcedo de Oliveira examina as reflexões, registradas em portfólios, de cinco estagiários de uma universidade do Sul do Brasil acerca da seguinte questão: o que eu aprendi, enquanto professor(a) de Língua Inglesa, durante meu estágio na FURG (Universidade Federal do Rio Grande) em 2015?

No sexto capítulo, Luana Francisleyde Pessoa de Farias e Tatiana Fernandes Sant'ana, professoras de universidades públicas na Paraíba e pesquisadoras que desenvolveram teses sobre o contexto do estágio supervisionado, analisam relatórios de duas professoras em formação inicial, focalizando, a partir do Interacionismo Sociodiscursivo e dos Estudos Culturais, o agir docente e a construção identitária. Phil Quirke, professor e pesquisador inglês que já trabalhou em diversos países, descreve, no capítulo "The core of this language teacher training programme is supervised practicums", um curso de formação de professores de Inglês (Bachelor of Education programme in English Language Teaching in Schools) ofertado pela maior instituição de ensino superior dos Emirados Árabes Unidos. Inicialmente, Quirke apresenta os principais fundamentos teóricos do curso. Em seguida, descreve como acontece o 


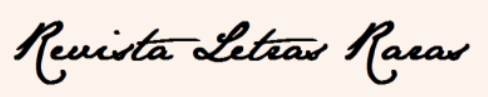

ISSN: $2317-2347$ - v. 8, n. 3 (2019)

estágio supervisionado - núcleo principal do curso, como o próprio título do capítulo indica - em cada um dos quatro anos da formação. Por fim, o autor detalha aspectoschave do curso, como a reflexão sobre a prática, a tutoria e a avaliação.

No oitavo capítulo, a professora da Faculdade de Educação da Universidade de Johannesburgo, na África do Sul, Leila Kajee investiga como vinte e cinco professores de Inglês em formação matriculados no estágio supervisionado daquele centro de ensino superior lidam com questões relacionadas à justiça social. A partir de entrevistas, Kajee buscou verificar tanto a compreensão desses docentes acerca dos significados de justiça social e de professor ativista quanto a possibilidade de desenvolvimento por esses professores de uma perspectiva de justiça social no contexto de estágio em que atuavam. Em “Gêneros de discurso na formação - saberes em diálogo na constituição da identidade acadêmica e profissional", Maria Angela Paulino Teixeira Lopes, professora da graduação e da pós-graduação em Letras da PUC-Minas com longa experiência na investigação de relatórios de estágio supervisionado, examina quatro gêneros produzidos por alunos do componente foco do livro, quais sejam: projetos de ensino, diários de campo, relatórios e entrevista de grupo focal. A partir de fundamentos teórico-metodológicos advindos da Análise do Discurso, do Interacionismo Sociodiscursivo, dos Estudos do Letramento e das investigações sobre identidade, Lopes aponta que o processo de constituição identitária dos professores em formação se dá a partir do diálogo, muitas vezes tenso, entre discursos vindos de diferentes espaços (da universidade, da escola-campo, do senso-comum, etc.).

No último capítulo do livro, Angélica Araújo de Melo Maia, Betânia Passos Medrado e Carla Lynn Reichmann, professoras do Departamento de Línguas Estrangeiras Modernas da Universidade Federal da Paraíba, focalizam o evento "Seminário de Estágio Supervisionado em Línguas Estrangeiras" (Sesle), desenvolvido semestralmente, desde 2014, pelo departamento em que trabalham, com o objetivo de possibilitar a partilha pelos estagiários das experiências vividas no contexto de estágio. A partir das análise de excertos de fala de professores de Inglês em formação inicial e de pôsteres apresentados no referido evento, as autoras apontam que o Sesle tem permitido o fortalecimento da escuta das vozes dos estagiários, que, por muito tempo, foram pouco ouvidos, e, consequentemente, de uma formação muito mais dialógica. Após esse capítulo, estão vinte páginas com todas as referências bibliográficas citadas 


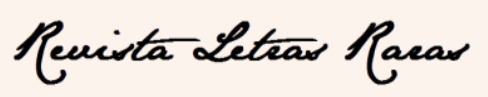

ISSN: 2317-2347 - v. 8, n. 3 (2019)

nos dez artigos do livro que, seguramente, poderão auxiliar o leitor a se aprofundar ainda mais na temática "estágio supervisionado".

Conforme é possível perceber a partir da descrição feita acima, o livro apresenta um relevante panorama sobre o estágio supervisionado na formação de professores de línguas - notadamente, Português e Inglês. Como já mencionado anteriormente, a coletânea é feita por profissionais de diversas localidades que realmente conhecem os contextos de estágio, pois não só são professores desse componente como também têm se dedicado a investigações contundentes sobre essa temática. Além disso, os capítulos focalizam vários aspectos do estágio e seus personagens (organização, identidade, gênero profissional, etc.), a partir de dados diversos (documentos prescritivos, relatórios, eventos, etc.) e de diferentes perspectivas teóricas (Análise do Discurso, Estudos Culturais, Interacionismo Sociodiscursivo, etc.).

Sendo assim, Horizontes (im)possíveis no estágio é leitura fundamental para os diretamente envolvidos - professores universitários, supervisores das escolas-campo e estagiários - com os componentes de estágio supervisionado de línguas nos cursos de Letras e Educação/Pedagogia e para aqueles docentes da academia que não necessariamente trabalham nesses componentes, mas participam de grupos de trabalhos, a exemplo do Núcleo Docente Estruturante (NDE), responsáveis por (re)pensar, no âmbito das universidades, os projetos pedagógicos, no caso aqui, das licenciaturas.

Citemos aqui apenas dois exemplos de convites à reflexão que esses leitores terão no contato com o livro. Ao final do capítulo do inglês Phil Quirke, o leitor provavelmente passará a refletir sobre a possibilidade da existência de estágios supervisionados desde o início dos cursos de licenciatura. Já o capítulo de Maia, Medrado e Reichmann, que evidencia a importância dos eventos de partilha das experiências vivenciadas na iniciação à docência, pode ser lido como um convite à criação desses espaços pelos cursos de licenciatura de línguas que ainda não os possuem ou ainda de ampliação daqueles que já se lançaram à empreitada de realizar eventos de estágio supervisionado. A leitura do livro organizado por Reichmann e Guedes-Pinto também será produtiva aos pesquisadores da temática "estágio supervisionado de línguas", que, felizmente, já não são mais poucos, pois esses identificarão caminhos já trilhados no que se refere a objetos e a teorias. 


\section{Reuista Leteas Racar}

ISSN: 2317-2347 - v. 8, n. 3 (2019)

Certamente Horizontes (im)possíveis no estágio: práticas de letramento e formação de professores de línguas contribui, a exemplos de outras publicações sobre a mesma temática, como os números especiais de periódicos científicos e as teses e dissertações, para a consolidação do estágio supervisionado nos cursos de formação de professores de línguas como objeto de estudo/investigação nas Ciências Humanas. 